\title{
Federica Locatelli, Une figure de l'expansion. La périphrase chez Charles Baudelaire
}

\section{Maria Emanuela Raffi}

\section{(2) OpenEdition}

1 Journals

\section{Edizione digitale}

URL: http://journals.openedition.org/studifrancesi/1415

DOI: $10.4000 /$ studifrancesi. 1415

ISSN: 2421-5856

\section{Editore}

Rosenberg \& Sellier

\section{Edizione cartacea}

Data di pubblicazione: 1 décembre 2015

Paginazione: 618-619

ISSN: 0039-2944

\section{Notizia bibliografica digitale}

Maria Emanuela Raffi, «Federica Locatelli, Une figure de l'expansion. La périphrase chez Charles

Baudelaire», Studi Francesi [Online], 177 (LIX | III) | 2015, online dal 01 décembre 2015, consultato il 09 janvier 2021. URL: http://journals.openedition.org/studifrancesi/1415 ; DOI: https://doi.org/10.4000/ studifrancesi. 1415

Questo documento è stato generato automaticamente il 8 janvier 2021.

\section{(c) (1)}

Studi Francesi è distribuita con Licenza Creative Commons Attribuzione - Non commerciale - Non opere derivate 4.0 Internazionale. 


\title{
Federica Locatelli, Une figure de l'expansion. La périphrase chez Charles Baudelaire
}

\author{
Maria Emanuela Raffi
}

\section{NOTIZIA}

FEDERICA LOCATELLI, Une figure de l'expansion. La périphrase chez Charles Baudelaire, Berne, Peter Lang, 2015, pp. 194.

1 Dedicato all'aspetto linguistico delle Fleurs du Mal, il saggio di Federica Locatelli è introdotto da una prefazione di Michel Deguy in cui la poesia è vista soprattutto come «débat» e la poetica come «Théorie du voisinage ou éloignement ou rapprochement(s)» e in cui la perifrasi, oggetto privilegiato dello studio, è indicata come la figura per eccellenza dell'avvicinamento e del détour, figura più creativa che comunicativa.

2 Lo studio è diviso in tre parti. Nella prima Federica Locatelli presenta un quadro d'insieme delle ricerche poetiche simboliste, sottolineando la necessità sentita dagli autori di rielaborare il linguaggio per farlo arrivare all'inesprimibile, al sogno, alla sacralità del mistero; tale sforzo comporta secondo l'A. un allargamento della retorica che deve corrispondere a questa nuova poetica, allargamento in cui Baudelaire ricopre un ruolo fondamentale. Dopo alcuni paragrafi dedicati alla definizione della figura della perifrasi sia sotto il profilo sintattico e lessicale che sotto quello semantico, anche utilizzando testi baudelairiani, l'autrice arriva a riconoscere alla figura la capacità di creare «dans la chaine du sintagme une 'ré-union' d'éléments à l'origine désagrégés, réordonnés selon la faculté synthétique de l'imagination artistique». L'A. analizza quindi, in tutta la parte centrale dello studio, questo strumento di ricerca poetica utilizzato da Baudelaire, applicandolo a tre categorie fondamentali: «l'individualité», «le temps»e «l'espace». 
3 Riprendendo il concetto di «nomination» utilizzato da Deguy come ricerca del senso, l'A. studia la presenza dei nomi propri nell'opera baudelairiana soprattutto nella «nomination biblique», comprensiva della ripresa di forme sintattiche, di parafrasi dalle Scritture e di trasposizioni dell'immaginario biblico.

4 La metafora del viaggio, che percorre largamente Les Fleurs fino all'approdo all'Inconnu, si manifesta anzitutto per l'autrice sull'asse temporale, attraverso il concetto di «Infini» e un'ossessione per il trascorrere del tempo particolarmente evidente in «L'Horloge» e «Les Sept Vieillards», poesie di cui mette in luce l'amplificazione operata dalla struttura perifrastica, all'opera anche in altri testi poetici («Harmonie du soir», «Crupuscule du soir», "Crepuscule du matin»), in cui appare tuttavia un diverso ordine temporale, infinitamente reiterato, creazione della poesia e sottratto all'ordine naturale. Questo «contretemps» poetico è ciò che caratterizza per l'A. la concezione baudelairiana del tempo, di cui la perifrasi appare emblema.

5 La dilatazione dello spazio, ultima operazione perifrastica esaminata, prende avvio dalla celebre affermazione di "Correspondances» («l'expansion des choses infinies») e accompagna tutto il viaggio del Poète: «le lieu du 'voyage' poétique apparaît ainsi comme une étendue immense, vague et indéfinie, se prolongeant «en haut, en bas, partout»: l'homme baudelairien voit l'Infini «par toutes les fenêtres». Segue un'analisi dettagliata dei diversi luoghi in cui, nell'itinerario delle Fleurs, si espande il soggetto baudelairiano: «Se plonger dans la ville», «Se plonger dans la mer», «Se plonger dans le gouffre».

Nello studio, arricchito da tre annexes sulle occorrenze di nomi propri e altri aspetti linguistici in alcuni importanti poeti della seconda metà dell'ottocento, preme con una certa evidenza la volontà di annettere tout court Baudelaire al Simbolismo e di sorvolare sull'uso di termini realistici e non vaghi spesso presenti nelle Fleurs. In questa prospettiva, che fa quasi coincidere Baudelaire e Mallarmé, la perifrasi appare indubbiamente la figura centrale della raccolta poetica. 